\title{
Article
}

\section{Comparing the Online Learning Capabilities of Gaussian ARTMAP and Fuzzy ARTMAP for Building Energy Management Systems}

Mokhtar, Maizura and Howe, Joseph Mark

Available at http://clok.uclan.ac.uk/8170/

Mokhtar, Maizura ORCID: 0000-0003-0460-3696 and Howe, Joseph Mark (2013) Comparing the Online Learning Capabilities of Gaussian ARTMAP and Fuzzy ARTMAP for Building Energy Management Systems. Expert Systems with Applications, 40 (15). pp. 6007-6018. ISSN 0957-4174

It is advisable to refer to the publisher's version if you intend to cite from the work. http://dx.doi.org/10.1016/j.eswa.2013.05.024

For more information about UCLan's research in this area go to http://www.uclan.ac.uk/researchgroups/ and search for <name of research Group>.

For information about Research generally at UCLan please go to http://www.uclan.ac.uk/research/

All outputs in CLoK are protected by Intellectual Property Rights law, including Copyright law. Copyright, IPR and Moral Rights for the works on this site are retained by the individual authors and/or other copyright owners. Terms and conditions for use of this material are defined in the policies page. 


\section{Accepted Manuscript}

Comparing the Online Learning Capabilities of Gaussian ARTMAP and Fuzzy ARTMAP for Building Energy Management Systems

Maizura Mokhtar, Joe Howe

PII: S0957-4174(13)00310-2

DOI: http://dx.doi.org/10.1016/j.eswa.2013.05.024

Reference: ESWA 8564

To appear in:

Expert Systems with Applications

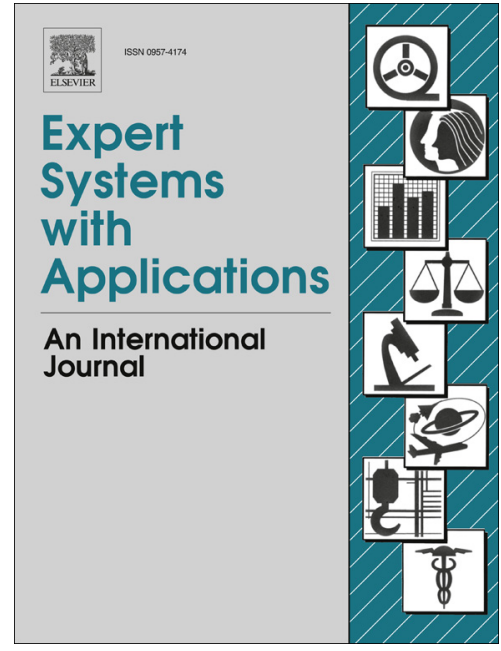

Received Date: $\quad 13$ April 2013

Accepted Date: $\quad 2$ May 2013

Please cite this article as: Mokhtar, M., Howe, J., Comparing the Online Learning Capabilities of Gaussian ARTMAP and Fuzzy ARTMAP for Building Energy Management Systems, Expert Systems with Applications (2013), doi: http://dx.doi.org/10.1016/j.eswa.2013.05.024

This is a PDF file of an unedited manuscript that has been accepted for publication. As a service to our customers we are providing this early version of the manuscript. The manuscript will undergo copyediting, typesetting, and review of the resulting proof before it is published in its final form. Please note that during the production process errors may be discovered which could affect the content, and all legal disclaimers that apply to the journal pertain. 


\title{
Comparing the Online Learning Capabilities of Gaussian ARTMAP and Fuzzy ARTMAP for Building Energy Management Systems
}

\author{
Maizura Mokhtar ${ }^{\mathrm{a}}$, Joe Howe ${ }^{\mathrm{a}}$ \\ ${ }^{a}$ School of Computing, Engineering and Physical Sciences, University of Central Lancashire, \\ Preston, PRI 2HE, UK (email: \{MMokhtar,JMHowe\}@uclan.ac.uk)
}

\begin{abstract}
Recently, there has been a growing interest in the application of Fuzzy ARTMAP for use in building energy management systems or EMS. However, a number of papers have indicated that there are important weaknesses to the Fuzzy ARTMAP approach, such as sensitivity to noisy data and category proliferation. Gaussian ARTMAP was developed to help overcome these weaknesses, raising the question of whether Gaussian ARTMAP could be a more effective approach for building energy management systems? This paper aims to answer this question. In particular, our results show that Gaussian ARTMAP not only has the capability to address the weaknesses of Fuzzy ARTMAP but, by doing this, provides better and more efficient EMS controls with online learning capabilities.
\end{abstract}

Keywords: Artificial Neural Network, Adaptive Resonance Theory, ARTMAP, Gaussian Distribution, Gaussian Classifier.

\section{Introduction}

Fuzzy Predictive Adaptive Resonance Theory (ART), better known as Fuzzy ARTMAP, was developed by Carpenter et. al., 1992 [1] to provide, in response to input patterns: fast and stable online recognition learning through the process of incremental supervised learning of recognition categories and multi-dimensional mapping, and hypothesis testing and adaptive naming. Fuzzy ARTMAP, a kind of artificial neural network (ANN), often outperforms other types of feedforward ANN [1]-[4]. This is because traditional feedforward ANNs, such as the multi-layer perceptron neural network, incorporate learning schemes that are slow learning models and are learned on the average order of the occurrences of its inputs [1]. An example of this is the back error propagation. Such learning mechanisms can also cause the ANN to degrade easily when they are exposed to new information. For example, in the context of building energy management systems or EMS, how the dynamic changes in the outdoor temperature can affect the output of the EMS-based ANN.

Fuzzy ARTMAP incrementally clusters multi-dimensional input vectors into stable categories. This incremental learning process prevents the previously learned maps to be significantly affected when exposed to new information. This has led to the growing interest in the application of Fuzzy ARTMAP for use in energy applications.

Examples of the application of Fuzzy ARTMAP for use in energy applications include:

1. Fault detection and identification: whereby the authors of [5] describe the use of Fuzzy ARTMAP for fault diagnostics of complex multi circuit transmission systems under various system and fault conditions. Authors of
[6] describes the employment of the Fuzzy ARTMAP pattern recognition technique to recognise the frequency responses of the winding admittance of high voltage transformers under varying conditions of winding insulation, and to also learn to establish the correlations between the nature and physical location of occurrence of an internal insulation fault in a transformer winding and its associated frequency response. Authors of [7] present the application of Fuzzy ART-ARTMAP to analyse the transient stability analysis of electric energy systems. Fuzzy ART-ARTMAP is a type of ANN that consists of the Fuzzy ARTMAP with an additional Fuzzy ART module (Section 2.1). Lastly, the authors of [8] describe the use of Fuzzy ARTMAP as part of a decision making tool that performs automatic detection and classification of voltage disturbances that can affect power quality of the energy distribution system.

2. Forecasting and prediction: Authors of [9] describe the use of Fuzzy ART-ARTMAP for electric load forecasting. Authors of [10] present the capabilities of Fuzzy ARTMAP to perform hourly day-type outputs prediction, based on which, generation can be forecasted. Authors of [11] indicates how Fuzzy ARTMAP can be applied to predict short wind speed, that can increase the effectiveness of wind power integration to the existing grid. Fuzzy ARTMAP is also shown capable of predicting the outlet temperature of the absorption system that utilises a set of solar collectors that satisfies the thermal necessities of the vapour generator, with good efficiency. This is as described in [12].

3. Building energy control: we have presented the results of applying the Fuzzy ARTMAP that can perform thermal comfort management and energy source control for a university building [13]. Fuzzy ARTMAP is shown to out 
perform the existing building management system.

Other applications include: medical applications [14]-[15], data classification [3]-[4], [16]-[17] and financial prediction [18].

There are, however, weaknesses to the Fuzzy ARTMAP. These were first identified by Williamson, 1996 [2]. The two main weaknesses are: (i) its sensitivity to noisy data, and (ii) inefficient fuzzy category generation. These weaknesses may affect the accuracy of the Fuzzy ARTMAP when it is in use. For EMS applications, this may reduce the EMS accuracy due to "noise" produced by dynamic weather conditions. Williamson, 1996 [2] has developed the Gaussian ARTMAP to help address these weaknesses.

This paper analyses the properties of Gaussian ARTMAP and Fuzzy ARTMAP, and investigates which of the two is better suited for use in a building energy management system with online learning capabilities. The paper is organised as follows: Section 2 provides a brief introduction to the Fuzzy ARTMAP. Section 3 details its weaknesses. Section 4 summarises the Gaussian ARTMAP, reiterating its development from the Fuzzy ARTMAP. Section 5 describes the example building energy management system used to conduct the comparative analysis, and how online learning is performed. Section 6 presents results and analysis. Section 7 concludes the paper.

\section{Fuzzy ARTMAP}

Fuzzy ARTMAP creates a map of the correlated pairs $\{a, b\}$, where $a$ is a set of inputs and $b$ is either:

1. the predictive consequences of the inputs, or

2. the category definition of the presented inputs for a classification problem.

Fuzzy ARTMAP provides fast learning capabilities by conjointly maximising generalisation and minimising predictive error, in real time, in response to an arbitrary ordering of its input patterns, using only local information. Fuzzy ARTMAP consists of two Fuzzy Adaptive Resonance Theory (Fuzzy ART) modules: Fuzzy ARTa and Fuzzy ARTb, which receive the inputs $a$ and $b$ respectively. The two Fuzzy ARTs are connected by an inter-ART module, which also resembles a Fuzzy ART. Further information on Fuzzy ART and inter-ART are provided in Sections 2.1 and 2.2 respectively.

\subsection{Fuzzy ART}

A Fuzzy ART consists of an attentional subsystem (Section 2.1.1) and an orienting subsystem (Section 2.1.2).

\subsubsection{Attentional subsystem}

In the attentional subsystem, a vigilance parameter $\rho$ calibrates the minimum confidence that a Fuzzy ART must have for the chosen recognition category to be activated by the inputs. This is instead of searching for another category activation through a process of hypothesis testing. The recognition category is provided by the orienting subsystem (Section 2.1.2). A cycle of hypothesis testing is triggered if the degree of match is less than $\rho$. This is called a match function. The degree of match provides a measure of predictive confidence that indicates if the chosen recognition category represents $a$, or the novelty of $a$ with respect to the hypothesis $b$ is symbolically represented by its recognition category [1].

Hypothesis testing terminates in a sustained state of resonance that persists as long as the input remains approximately constant. The resonance generates a focus of attention at the attentional subsystem that selects the bundle of critical features common to inputs $a$ or $I=\left(I_{1}, \ldots, I_{M}\right) . M$ is the number of inputs. The resonating categories produced are $\left(j_{1}, \ldots, j_{N}\right) . N$ is the number of categories.

Each category node $j$ is associated with an adaptive weight vector $w=\left(w_{j_{1}}, \ldots, w_{j_{M}}\right)$. The adaptive weights create the long term memory or LTM traces for the Fuzzy ARTMAP. Each LTM trace $w_{j_{i}}$ is monotone non-increasing through time (1) and converges to a limit.

$$
w_{j}^{(\text {new })}=\beta\left(I \wedge w_{j}^{(\text {old })}\right)+(1-\beta) w_{j}^{(\text {old })}
$$

$\beta$ is the learning rate parameter $\beta \in[0,1]$ and $a \wedge b=\min (a, b)$.

Monotone non-increasing is achieved through a step called complement coding. Complement coding incorporates the oncell of the input $a$ and its off-cell $a^{c}=1-a$. Complement coding normalises the inputs while preserving the amplitudes of its features. Without complement coding, a Fuzzy ART category only encodes the degree to which its critical features are consistently present in the training of that category. With complement coding, both the degree of absence and the degree of presence of features are represented by the category weight vectors. Without this additional processing, this could lead to category proliferation as too many adaptive weights will converge to zero.

For each input $I$ that activates node $j$, the recognition category $T_{j}$ is defined by (2).

$$
T_{j}(I)=\frac{\left|I \wedge w_{j}\right|}{\alpha+\left|w_{j}\right|}
$$

$|p| \equiv \sum_{i=1}^{M}\left|p_{i}\right|, \alpha$ is the choice parameter and $\alpha>0 . \alpha \rightarrow$ 0 because small values of $\alpha$ tend to minimise recoding of $w_{J}$ during learning or resonance. Moreover, during resonance, if $w_{J}$ is a subset of $I, w_{J}$ should remain unchanged and is therefore conserved (3).

$$
\left|I \wedge w_{J}\right|=\left|w_{J}\right|
$$

Resonance occurs if the match function (4) of the chosen category $J$ meets $\rho$ or $|x|=\left|I \wedge w_{J}\right|$, when $\left|I \wedge w_{J}\right| \geq \rho$.

$$
\frac{I \wedge w_{J}}{I} \geq \rho
$$

If otherwise, mismatch reset occurs and $w_{J}=1$.

In short, within the attentional subsystem, the activity vector $x$ obeys (5). 
$x= \begin{cases}I, & \begin{array}{l}\text { If input } I \text { is novel and no recognition category } \\ \text { is activated and cannot represent the inputs. }\end{array} \\ I \wedge w_{J}, & \begin{array}{l}\text { If otherwise, a recognition category is activated } \\ \text { and } J^{t h} \text { node is chosen. }\end{array}\end{cases}$

\subsubsection{Orienting subsystem}

Fuzzy ART makes a category choice (the chosen recognition category that best represents the inputs) when at most one $J$ has become active (2)-(5). The category choice is chosen using (6) and is indexed by $J$; and that $J$ satisfies (4).

$$
T_{J}=\max \left\{T_{j}: j=1, \ldots, N\right\}
$$

\subsection{Inter-ART}

The inter-ART module consists of a map field, which controls the learning of an associative map from Fuzzy ARTa recognition categories to the Fuzzy ARTb recognition categories. A recognition category classifies inputs or similar properties into one category. Inter-ART allows the mapping between the $a$ recognition categories to the $b$ recognition categories to not directly associate each other, but rather, associates the symbolic representation between the two recognition categories [1].

The map field also controls match tracking of the Fuzzy ARTa and Fuzzy ARTb recognition categories. Match tracking is designed to create the minimal number of Fuzzy ARTa recognition categories needed to meet the accuracy criteria described by the match function and to prevent category proliferation. Match tracking prevents category proliferation by employing the minimax learning rule. The minimax learning rule utilises a vigilance parameter $\rho$. $\rho$ of Fuzzy ARTa $\left(\rho_{a}\right)$ is increased by the minimum amount required to search for and if necessary learn of a new Fuzzy ARTa category that closely matches the category activation produced by Fuzzy ARTb. The increase in $\rho_{a}$ is instigated by a predictive failure at Fuzzy ARTb, which sacrifices the minimum amount of generalisation necessary to correct the predictive error at Fuzzy ARTb.

The minimax learning rule enables the Fuzzy ARTMAP to learn quickly, efficiently, and accurately as it conjointly minimises predictive error and maximises predictive generalisation. Inter-ART $\rho$, therefore, performs back propagation of information, whereby the search initiated by inter-ART can shift the attention to a novel cluster of features that can be learned into a new Fuzzy ARTa recognition category that better predicts $b$. The lower the value of $\rho_{a}$, the larger the categories are formed. Lower value of $\rho_{a}$ leads to a broader generalisation, higher code compression and smaller categories compactness [1].

\section{Weaknesses of Fuzzy ARTMAP}

As described in the Introduction, Williamson, 1996 [2] indicates that Fuzzy ARTMAP has two potential weaknesses: (i) sensitivity to noise and (ii) inefficient category creation.

\subsection{Sensitivity to noise}

When the Fuzzy ARTMAP makes a false prediction (i.e, the recognition category of Fuzzy ARTa does not match that of Fuzzy ARTb), a new category is created. If the input falls near the boundary between two categories, the newly created category will be small enough to fit within this space.

When the training data is noisy, the categories within the feature spaces are created randomly in response to the different predictions. The random creation of categories result in the category proliferation. Category proliferation is also partly due to the use of large $\rho$ value that allows for the fast learning mechanism. Reducing $\rho$ may address this issue.

\subsection{Inefficient categories}

The minimax learning rule indicates the categories are created with the simplest statistics of the data: the minimum and maximum values of the category range created to conjointly minimise the predictive error and maximise the predictive generalisation. This creates a rectangular classification of data which may not be suitable for the classification of the data. Williamson, 1996 [2] indicated that this method is best suited to data that are uniformly distributed within a category.

Williamson, 1996 also [2] points out: if the problem scales to higher dimension, the ratio of the hypersphere volume to the hyper-rectangular volume with equal diameter against that of its dimension, as feature spaces approaches higher dimensions, the volume of the hyper-rectangular category will be dominated by the corners. He has developed the Gaussian ARTMAP to address this issue.

\section{Gaussian ARTMAP}

Gaussian ARTMAP replaces the minimax learning rule within the Fuzzy ART with a Gaussian classifier. This, therefore, creates a Gaussian ART. Gaussian classifier is in place of the minimax learning rule, because Williamson, 1996 [2] indicated that the minimax learning rule is ill-posed and the smooth mapping of input-to-output is one of the weakest and most general assumption to make. He indicated that a priori assumptions are required and the use of Gaussian distribution is ideal. Gaussian classifier creates a category based on the Gaussian distribution of the data, with mean, variance and a prior probability used to define the category. Hence, the introduction of the Gaussian ARTMAP.

\subsection{Learning}

Gaussian ARTMAP is an incremental learning Gaussian classifier, in which each output is determined during training to correspond to any numbers of sources of the Gaussian distributed data. One limitation to this is that the Gaussian ART can fit the variance along a dimension, but not covariance between the dimensions. However, Williamson, 1996 [2] indicated that separable Gaussian ART allows the Gaussian ART to have storage and computational requirements similar to that of the Fuzzy ART. 
Each Gaussian ART category $j$ is defined by M-dimensional vector mean $\mu_{j}$ and variance $\sigma_{j}^{2}$. The number of training samples it has coded is given by $n_{j}$. Therefore, Gaussian ART category requires $2 M+1$ components to represent the $M$ dimensional input $I=\left\{I_{1}, \ldots, I_{M}\right\}$.

When a new category is generated, $I_{J}=\mu_{J}$. When a category $J$ learns an input sample $I, n_{J}, \mu_{J}$ and $\sigma_{j i}^{2}$ are updated using (7)(9) to represent the current sample vector.

$$
\begin{gathered}
n_{J}:=n_{J}+1 \\
\mu_{J}:=\left(1-n_{J}^{-1}\right) \mu_{J}+n_{J}^{-1} I \\
\sigma_{J i}^{2}:= \begin{cases}\left(1-n_{J}^{-1}\right) \sigma_{J i}^{2}+n_{J}^{-1}\left(\mu_{J i}-I_{i}\right)^{2} & \text { if } n_{j}>1 \\
\gamma^{2} & \text { otherwise }\end{cases}
\end{gathered}
$$

$\gamma^{2}$ is the variance initialisation parameter that determines the isotropic spread in the feature space of a new category's distribution about its first sample.

\subsection{Choice function}

The choice function picks the most likely category for a given input. A category's likelihood is determined by the likelihood that the input belongs to its distribution, as well as by the category's a priori probability used to define the category.

The Gaussian ART chooses the recognition category $J$, with the maximum discriminant given its input I is given by (10) [2].

$$
J=\max \left\{g_{j}(I): j=1, \ldots, N\right\}
$$

$N$ is the number of category activated.

$$
\begin{aligned}
& g_{j}(I)= \log \left((2 \pi)^{\frac{M}{2}} p(I \mid j) P(j)\right) \\
&=-\frac{1}{2} \sum_{i=1}^{M} \frac{\left(\mu_{j i}-I_{i}\right)^{2}}{\sigma_{j i}^{2}} \\
&-\frac{1}{2} \log \left(\prod_{i=1}^{M} \sigma_{j i}^{2}\right)+\log (P(j)) \\
& P(j)=\frac{n_{j}}{\sum_{j^{\prime}=1}^{N} n_{j^{\prime}}}
\end{aligned}
$$

\subsection{Match function}

The match function is based solely on the likelihood that the input belongs to a category distribution, discounting its a prior probability (13).

$$
\begin{aligned}
g_{j}^{\prime}(I) & =g_{J}(I)-\log (P(J)) \\
& =\log \left((2 \pi)^{\frac{M}{2}} p(I \mid j)\right) \\
& =-\frac{1}{2} \sum_{i=1}^{M} \frac{\left(\mu_{j i}-I_{i}\right)^{2}}{\sigma_{j i}^{2}}-\frac{1}{2} \log \left(\prod_{i=1}^{M} \sigma_{j i}^{2}\right)
\end{aligned}
$$

The Gaussian ARTMAP provides the prediction output that is interpreted as picking the class with the highest net probability. Therefore all category predictions are summed to yield the most likely net prediction of a class, rather than basing the prediction on the maximum Fuzzy ART category.

In summary, the replacement of the minimax learning rule with the Gaussian classifier can address the two weaknesses of Fuzzy ARTMAP. Gaussian classifier that incorporates Gaussian distribution, with their smoothness and generalisation properties, are also ubiquitous to real world conditions. This is because the distribution of information in the real world is the result of the summation of independent random variables occurring in the environment [2]. The energy management systems are a good example of the real world applications that are susceptible to the randomness of a dynamic environment.

\section{Building Energy Management System}

There are a number of energy management systems (EMS) developed with the incorporation of Fuzzy ARTMAP. Examples of this are that described in [5]-[13] $]^{1}$.

This paper presents a similar case study to that presented in [13]; however, limiting the analysis to just the boiler controls for the building. The boilers are used to heat and maintain the hot water temperature required by the centralised heating system. The aim of the EMS is to ensure that the hot water produced can maintain the building to its desired temperature values.

The boiler controls are developed with the Fuzzy ARTMAP and Gaussian ARTMAP, separately. Fuzzy ARTMAP and Gaussian ARTMAP are compared to identify which of the two is better at:

Function 1 Providing the required switching mechanism for the boilers system: ON $\leftrightarrow$ OFF.

Function 2 Indicating the desired hot water temperature to be maintained by the boilers.

Fuzzy ARTMAP and Gaussian ARTMAP are to provide these two functionalities given the desired and actual building (indoor) and environment (outdoor) temperatures.

\subsection{Online learning}

In common with other ANNs, the main disadvantage of Fuzzy ARTMAP and Gaussian ARTMAP is that their blackbox characteristics limit the users' ability to analyse the inputto-output relationships established by the network. Due to this limitation, an additional component is added to both the Gaussian ARTMAP and Fuzzy ARTMAP. This component, labelled Supervisor in Figure 1 allows seamless interactions between the Gaussian ARTMAP and the Fuzzy ARTMAP and its users. This will help promote transparency for the EMS.

\footnotetext{
${ }^{1}$ In [13], the authors indicated the use of ARTMAP, but the functionalities employed by the EMS are that of the Fuzzy ARTMAP
} 
When new thermal and energy characteristics are required by the building, the user will instigate the learning of the new characteristics by presenting the new desired configuration to the input of ART $b$ (Figure 1). The presented supervisory information corresponds to the input data provided to ART a.

The Supervisor will monitor the input presented to and output provided by the Gaussian ARTMAP or the Fuzzy ARTMAP. The Supervisor indicates when the Gaussian ARTMAP or the Fuzzy ARTMAP has adapted its network to the new input-to-output relationships. This seamless instigation of learning allows the adaptation of the Gaussian ARTMAP or the Fuzzy ARTMAP without any need to re-code the software infrastructure. This will promote and ensure transparency of the EMS.

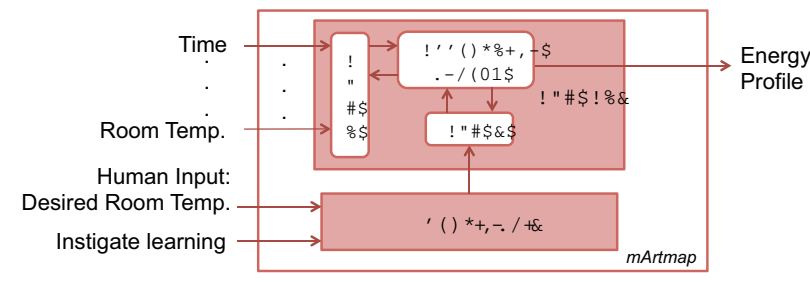

Figure 1: Supervisor monitors the online learning for the EMS.

\subsection{Inputs to the ARTMAP}

Inputs to the Fuzzy ARTMAP and Gaussian ARTMAP are:

1. Current date and time.

2. $O_{T}(t), O_{T}(t-1), O_{T}(t-2), O_{T}(t-3), O_{T}(t-4)$. $O_{T}$ is the outdoor temperature. $O_{T}(t-x)$ is the outdoor temperature at the previous $x$ hour.

3. $I_{y}(t), I_{y}(t-1), I_{y}(t-2), I_{y}(t-3), I_{y}(t-4) . I_{y}$ is the average building $y$ temperature. $I_{y}(t-x)$ is the average building $y$ temperature at the previous $x$ hour. Average building $y$ temperature is calculated by averaging the measured temperature values of all rooms in the building.

4. $W_{O}(t), W_{O}(t-1), W_{O}(t-2), W_{O}(t-3), W_{O}(t-4) . W_{O}$ is the return water temperature from the building. $W_{O}(t-x)$ is the return water temperature from the building at the previous $x$ hour.

5. $W_{I}(t), W_{I}(t-1), W_{I}(t-2), W_{I}(t-3), W_{I}(t-4) . W_{I}$ is the provided water temperature for the building $W_{I}(t-x)$ is the provided water temperature for the building at the previous $x$ hour.

6. Instigate learning $=1$ : The user forces the Gaussian ARTMAP and the Fuzzy ARTMAP to learn of a new hot water temperature setting for the boiler. The Supervisor (Figure 1) provides the output Learn $=1$.

Instigate learning $=0$ : The user is happy with the provided heat and the Supervisor provides the output Learn $=0$.

When Instigate learning $=1$, the user sets the hot water temperature for the boilers, and learning is instigated for Gaussian ARTMAP and the Fuzzy ARTMAP with the new desired hot water temperature setting for the boilers.
(1)-(3) are the inputs indicating the energy demand. (4)-(5) are the inputs indicating the energy resource. (6) is the human interrupting signals to the Supervisor.

During the learning period (Instigate learning = 1), the Gaussian ARTMAP or the Fuzzy ARTMAP takes in the user desired temperature setting and learns of the desired switching (Function 1) and hot water temperature setting for the boilers (Function 2). The Supervisor sets the signal Learn $=1$ and helps provide the desired value for learning according to the following rules:

If building temperature $>$ desired building temperature

Then boiler switch $=\mathrm{OFF}$;

Else if the building temperature <

(desired building temperature $-2^{\circ} C$ )

Then boiler switch $=\mathrm{ON}$;

The desired room (or building) temperature is set to $23^{\circ} \mathrm{C}$. The hot water temperature is set to $80^{\circ} \mathrm{C}$ when high heat demand is required (for example, during the winter months); and less (for example to be maintained at $2 \mathrm{x}$ room temperature) if there is lesser heat demand. Learning stops (Learn switches 1 $\rightarrow 0$ ) when the building temperature = desired building temperature after a suitable time period (six number of samples).

\subsection{Online learning}

In the experiments conducted for this paper, the Instigate learning signal is set at 0 . However, online learning does take place:

If desired building temperature $-2^{\circ} \mathrm{C}>$ building temperature or building temperature $>$ desired building temperature Then Learn $=1$ and learning of new classification is instigated.

During this learning period (Learn $=1$ ), Supervisor provides the following supervisory inputs:

If building temperature $>$ desired building temperature

Then boiler switch $=\mathrm{OFF}$ and

its desired hot water temperature setting is linearly reduced until building temperature $\approx$ desired building temperature.

If desired building temperature $-2^{\circ} C>$ building temperature Then boiler switch $=\mathrm{ON}$ and

the desired hot water temperature setting is linearly increased until the building temperature $\approx$ desired building temperature.

Learning stops $($ Learn $=0)$ when the building temperature $\approx$ desired building temperature after six samples.

At the start of the simulation/experiment, both the Fuzzy ARTMAP and the Gaussian ARTMAP have one classification: boiler switch $=\mathrm{ON}$, desired hot water temperature $=80^{\circ} \mathrm{C}$ and Learn $=1$. The inputs and outputs from the Fuzzy ARTMAP and Gaussian ARTMAP are sampled and provided every 15 minutes. Fuzzy ARTMAP vigilance parameter $\rho=0.75$. The outputs produced are in response to the provided outdoor temperatures between $5^{\text {th }}$ March 2012 to $25^{\text {th }}$ May 2012; omitting the values between 22 $2^{\text {nd }}$ March 2012 09:00 to $24^{\text {th }}$ March 2012 22:25 because no temperature data were collected during these time. The outdoor temperature is depicted in Figure 2. 


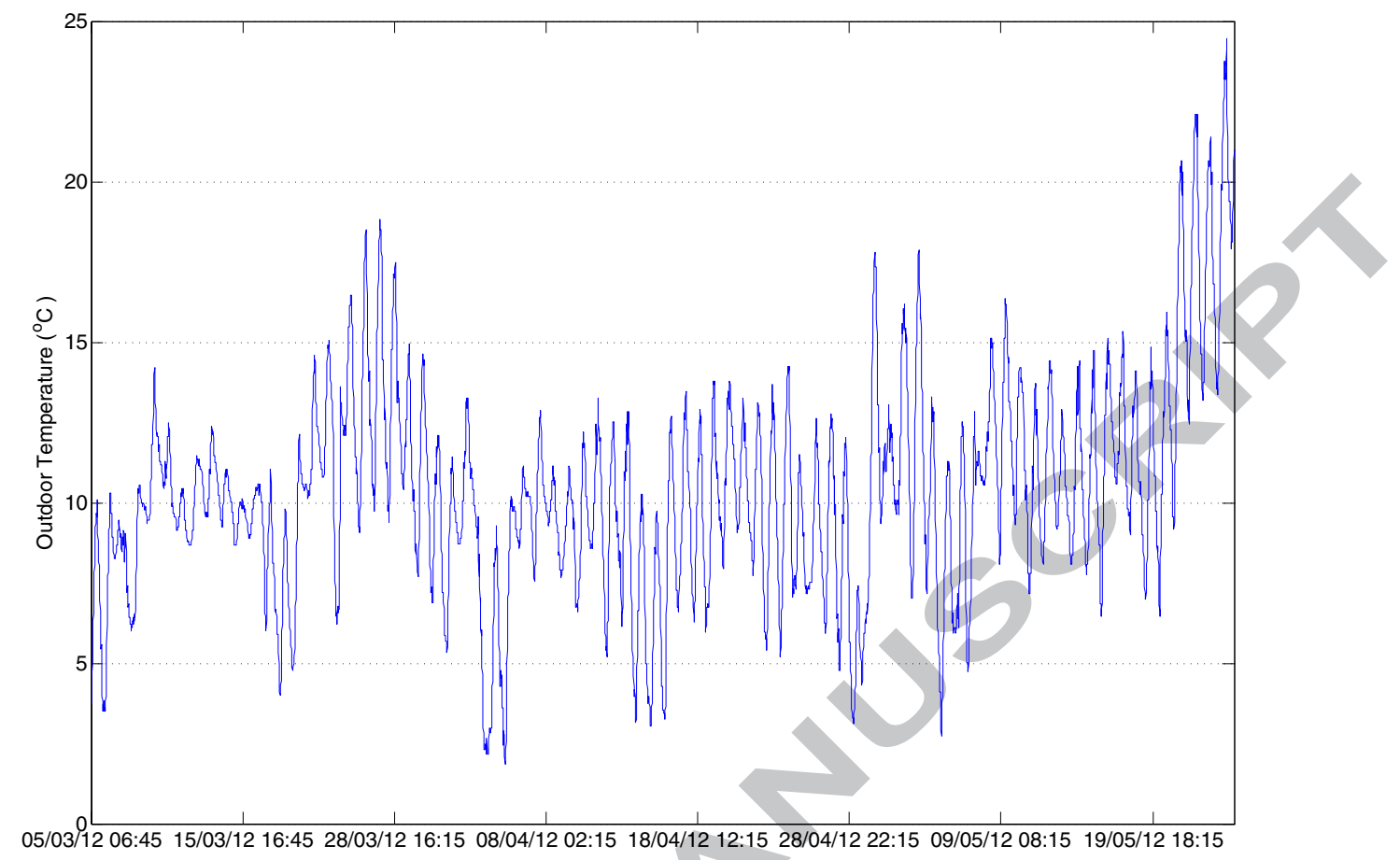

\section{Results}

6.1. Function 1: Providing the required switching mechanism

Four categories of switching outputs are produced by the Gaussian and Fuzzy ARTMAP. The switching output are produced given the simulated building temperatures, boilers water temperatures and output temperatures. The four are:

Blue $\circ$ indicates that the Gaussian and Fuzzy ARTMAP have created a new category that causes the boilers to be switched ON. A new category is created when no recognition category is activated. When this occurs, Learn $=$ 1.

Cyan + indicates that the Gaussian and Fuzzy ARTMAP have created a new category that causes the boilers to be switched OFF, and Learn $=1$.

Red $\diamond$ indicates the boilers are to be switched ON, and the inputs have activated a recognised category or are part of a learned category. Learn $=0$.

Magenta $*$ indicates the boilers are to be switched OFF, and the inputs have activated a recognised category (Learn $=$ $0)$.

Figures 3 and 4 show the results of the EMS. When comparing the two figures, it shows Gaussian ARTMAP provides a better categorisation of data (recognition categories) than that of the Fuzzy ARTMAP. This is because, when utilising the Fuzzy ARTMAP there are a large mix of:
1. New and learned categories, and

2. When the boiler switch has to be switched ON or OFF.

The large mix of new and learned recognition categories are because, when the input falls near the boundary between two learned categories, the inputs are considered as novel; and a new recognition category is to be generated. In this instance, the new recognition category is small in order to fit between the two categories. This causes the category proliferation. Fuzzy ARTMAP $\rho=0.75$.

\subsection{Function 2: Indicating the desired hot water temperature for the boilers}

Similar observations are seen when the Gaussian ARTMAP and the Fuzzy ARTMAP were used to categorise and indicate the desired hot water temperature to be produced and maintained by the boilers. By comparing the two figures in Figure 5, shows the Gaussian ARTMAP is better than the Fuzzy ARTMAP because, similar to the previous function (Section 6.1), the Gaussian ARTMAP provides:

1. Variable desired weather temperature to suit the variable demand of the building.

2. Lesser new recognition categories generated.

\subsection{Summary of results}

The figures shows the Gaussian ARTMAP has provided clear distinctions when the boilers should be switched ON in order to produce and maintain to the required hot water temperature and 


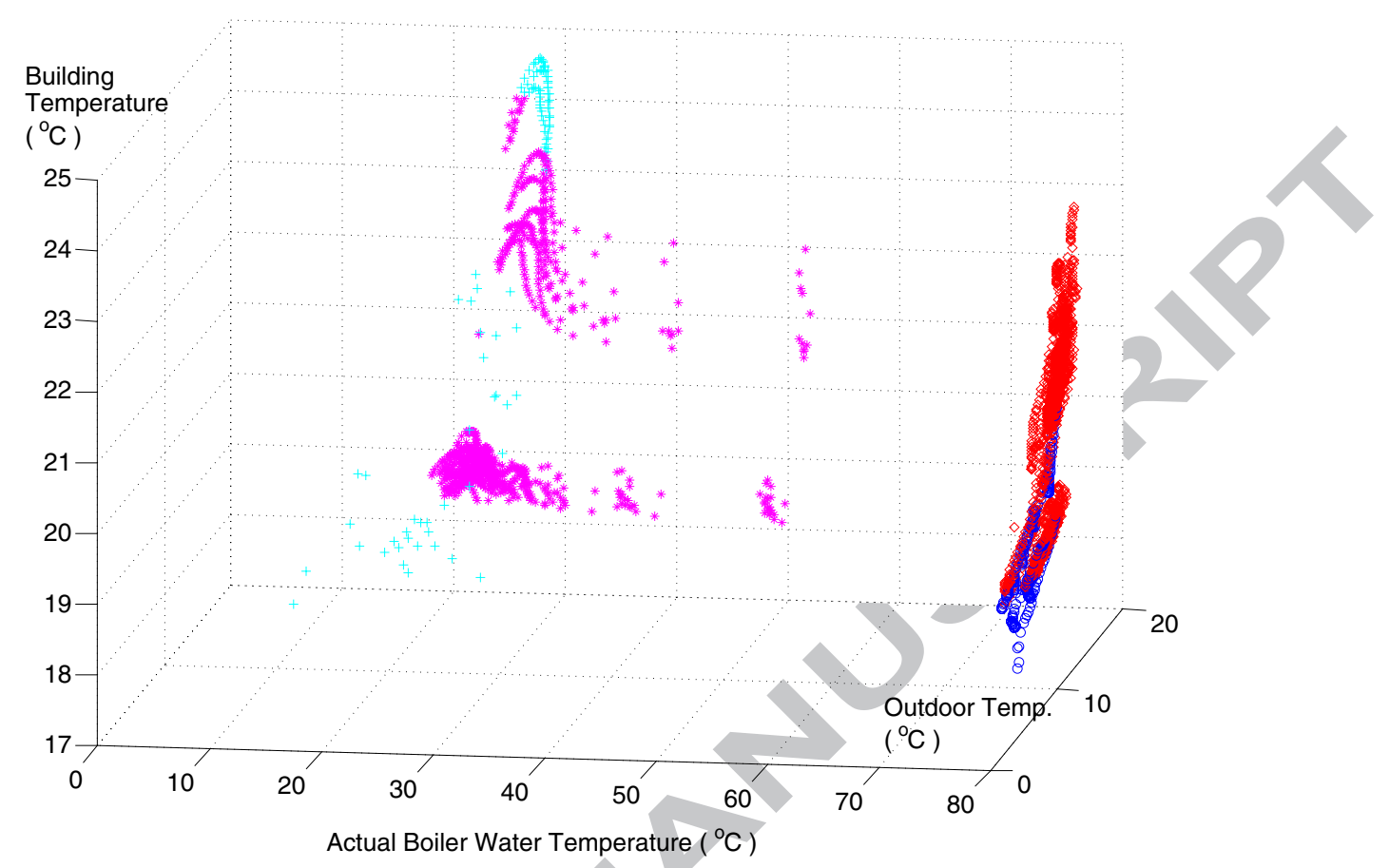

(a)

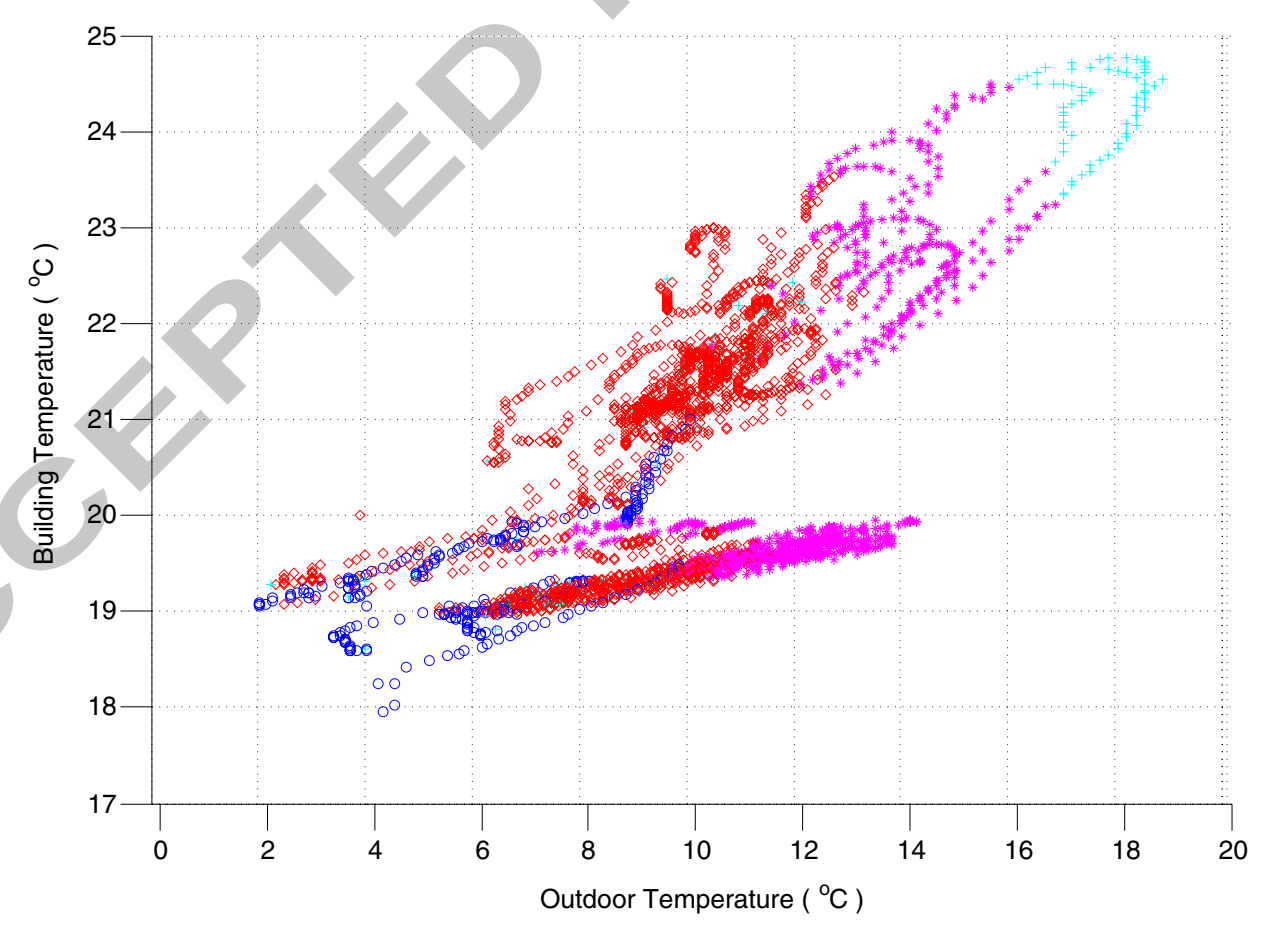

(b) Rotating Figure (a)

Figure 3: The four categories produced by Gaussian ARTMAP, with clear decision boundaries are made that indicates when best to switch ON or OFF the boilers (Function 1 described in Section 5). The definitions of the categories are described in Section 6.1. 


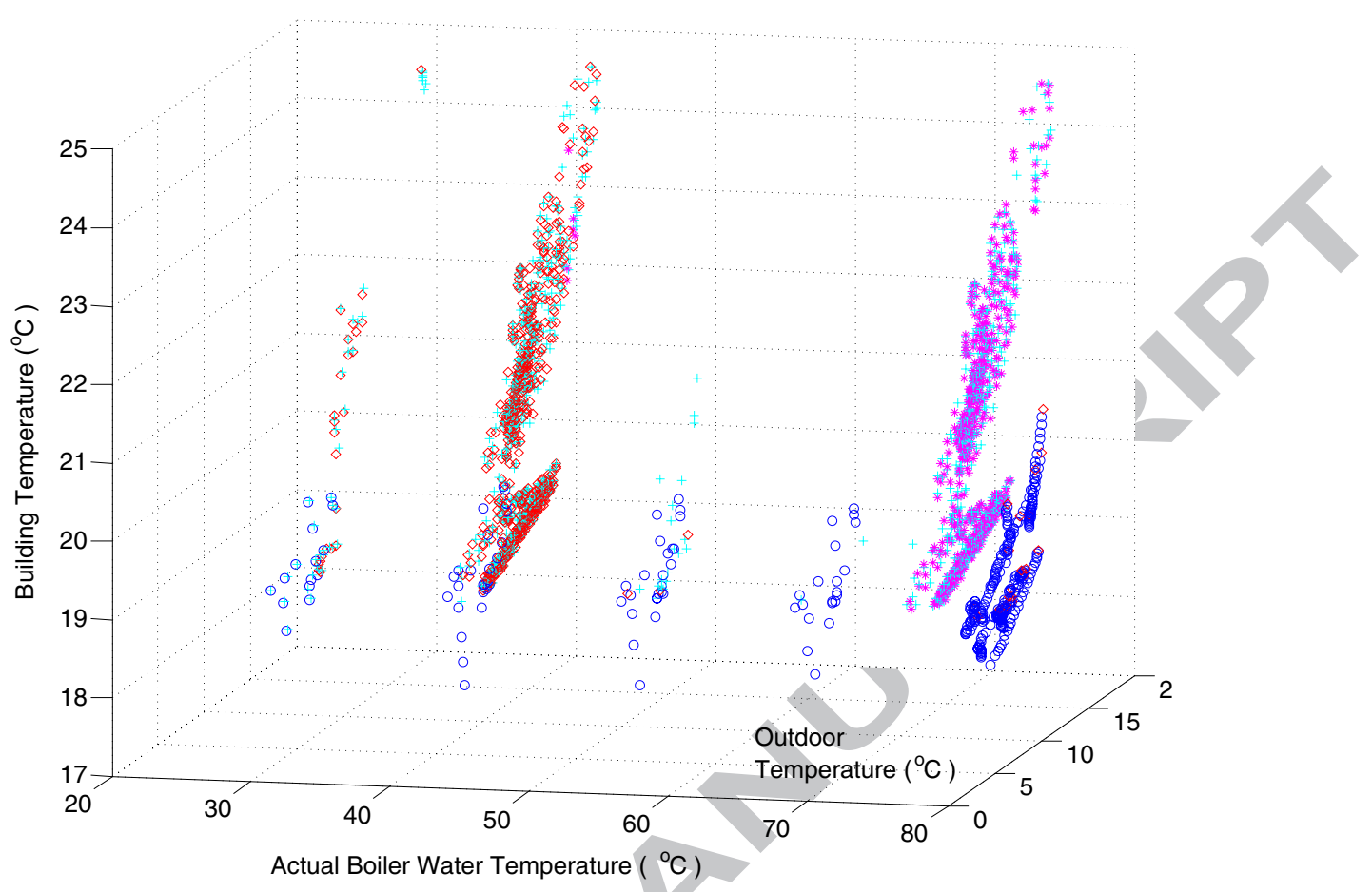

(a)

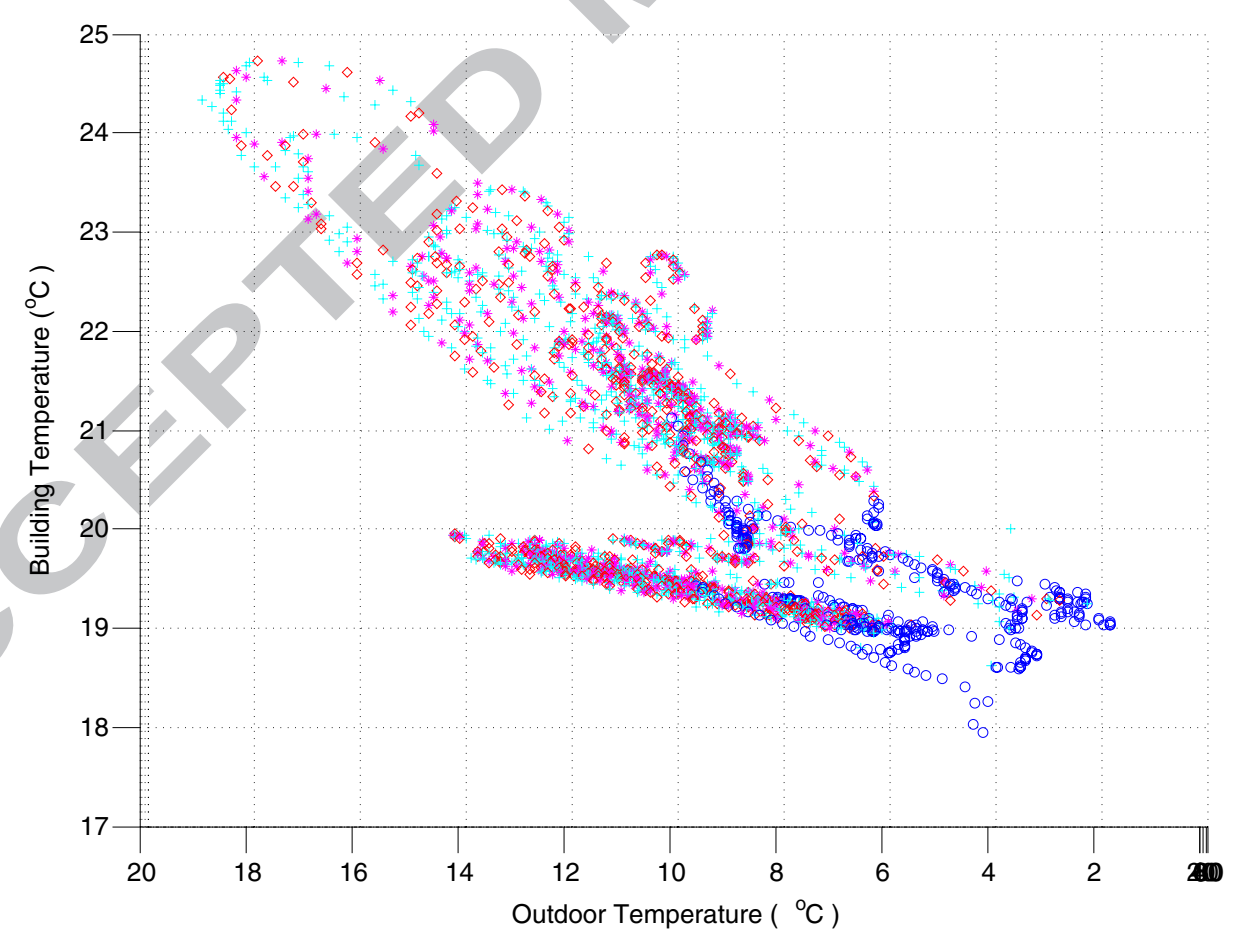

(b) Rotating Figure (a)

Figure 4: The four categories produced by Fuzzy ARTMAP indicating when best to switch ON or OFF the boilers (Function 1 indicated in Section 5). The definitions of the categories are described in Section 6.1. Large mixing of categories are resulted from category proliferations. 


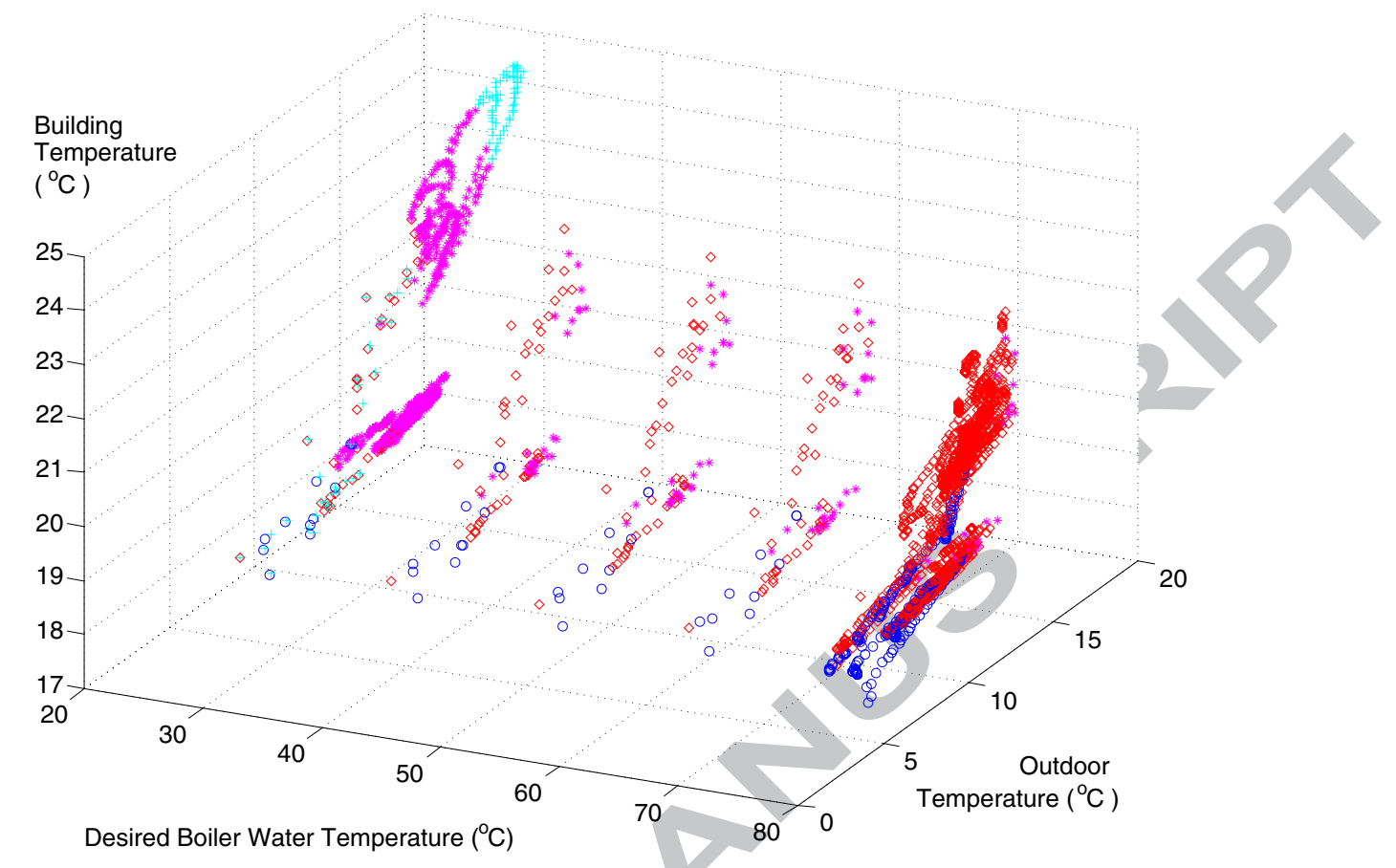

(a) Gaussian ARTMAP

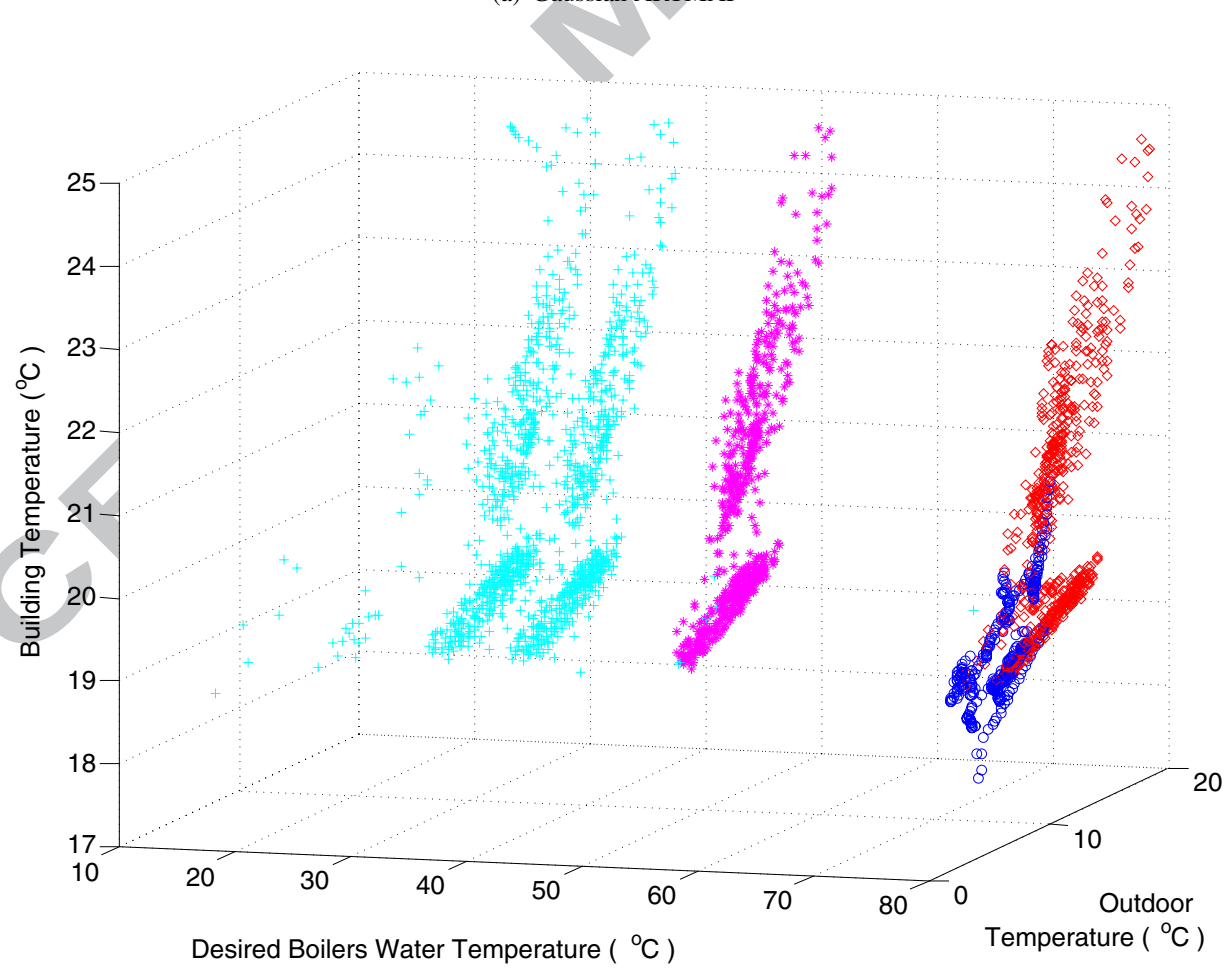

(b) Fuzzy ARTMAP

Figure 5: Comparing Gaussian ARTMAP and Fuzzy ARTMAP in indicating the desired hot water temperature for the boilers (Function 2 indicated in Section 5). Gaussian ARTMAP provides variable temperature settings for the boilers (blue $\circ$ and red $\diamond$ ), which helps minimise heat waste. 
when to switch OFF. The figures also show that the Gaussian ARTMAP indicates the need for hot water temperature when the output temperatures are low and the building temperatures are below the desired building temperature values. This clear distinction was not provided by the Fuzzy ARTMAP.

The clear decision boundary provided by the Gaussian ARTMAP can produce better switching mechanisms for the boilers system. This is shown when comparing the two figures in Figure 6, where the Gaussian ARTMAP provides lesser switching $\mathrm{ON} \leftrightarrow$ OFF of the boilers in comparison to the Fuzzy ARTMAP; as well as better at achieving the desired building temperature (Figure 7). The frequent switching provided by the Fuzzy ARTMAP is because of category proliferation or the creation of small categories generated at the occurrence of novel inputs. The high frequency of switching may, over time, reduce the efficiency of the boilers.

Gaussian ARTMAP provides similar output for the building with lesser switching frequency for the boilers system. This is shown in Figure 6.

\subsection{Varying the vigilance parameter $\rho$}

Carpenter et. al., 1992 [1] and Williamson, 1996 [2] have suggested that reducing the $\rho$ values can prevent category proliferation. Therefore, to investigate such effects, the building simulation model was simulated with Fuzzy ARTMAP $\rho=0.25, \rho=0.5$ and $\rho=0.9$. In the earlier Fuzzy ARTMAP simulation, $\rho=0.75$.

Table 1 shows the frequency of switching of the boilers with varying $\rho$ values. The table shows the higher the $\rho$ value, the higher the frequency of switching.

\begin{tabular}{c|c}
\multicolumn{2}{c}{ Table 1: Frequency of Switching for Different Values of Fuzzy ARTMAP $\rho$} \\
\hline$\rho$ & $\begin{array}{r}\text { Frequency = } \\
\text { Number of change in states / Number of states }\end{array}$ \\
\hline 0.25 & 0.1714 \\
0.50 & 0.1714 \\
0.75 & 0.1714 \\
0.90 & 0.1201 \\
\hline Gaussian & 0.0130 \\
ARTMAP
\end{tabular}

Furthermore, by comparing the switching outputs indicated in Figures 8-9, demonstrates that the category proliferation can be avoided, to an extent, by reducing the values of $\rho$. The figures show more new recognition categories are generated when $\rho=0.9$, in comparison to $\rho=0.5$.

\section{Conclusion}

There is a growing interest in the application of Fuzzy ARTMAP for use in energy management system. However, as this paper has demonstrated, there are weaknesses to the Fuzzy ARTMAP. The Fuzzy ARTMAP is sensitive to noisy data and category proliferations. The Gaussian ARTMAP was developed to address these weaknesses. This paper analysed which of the two ARTMAPs is better for use in building energy management system. Results indicated that despite reducing the $\rho$ values of the Fuzzy ARTMAP, Gaussian ARTMAP still provides better boiler controls than that of the Fuzzy ARTMAP. Gaussian ARTMAP provides:

1. Clearer decision boundaries: clearer definition on when to switch ON or OFF the boilers,

2. Clearer defined desired hot water temperature values required by the building given its building and environmental conditions (inputs), and

3. Lesser category proliferation.

This has resulted in lesser frequency of change in state (lesser frequency of switching between $\mathrm{ON} \leftrightarrow \mathrm{OFF}$ ) provided by the Gaussian ARTMAP; this is in comparison to the Fuzzy ARTMAP. Furthermore, high frequency of change in state, change between the $\mathrm{ON} \leftrightarrow$ OFF states, over time may reduce the effectiveness and efficiency of the building energy management system.

The Gaussian ARTMAP can also maintain greater consistency with the desired objective of the system: to more accurately maintain the desired building temperature. As a result of the analysis conducted, the Gaussian ARTMAP is the better choice for building energy management.

\section{Acknowledgement}

The authors would like express their gratitude to Matthew Stables and the UCLan Facilities Management in all their help in providing information with regards to the heat demand and resources of the Samuel Lindow Building. The work is joint funded by BAE Systems, UK. The authors would also like to thank Michael Lones for valuable comments on the paper.

\section{References}

[1] G. Carpenter, S. Grossberg, N. Markuzon, J. Reynolds, and D. Rosen, "Fuzzy ARTMAP: A neural network architecture for incremental supervised learning of analog multidimensional maps," IEEE Trans. Neural Networks, vol. 3, no. 5, pp. 698-713, 1992.

[2] J. Williamson, "Gaussian ARTMAP: A neural network for fast incremental learning of noisy multidimensional maps," Neural Networks, vol. 9, no. 5, pp. 881-897, 1996.

[3] R. Palaniappan, C. Eswaran, "Using genetic algorithm to select the presentation order of training patterns that improves simplified fuzzy ARTMAP classification performance," Applied Soft Computing, vol. 9, no. 1, pp. 100-106, 2009.

[4] Z. Liang, X. Bingang, Z. Chi, D. Feng, "Intelligent characterization and evaluation of yarn surface appearance using saliency map analysis, wavelet transform and fuzzy artmap neural network," Expert Systems with Applications, vol. 39, no. 4, pp. 4201-4212, 2012.

[5] R. K. Aggarwal, Q. Y. Xuan, A. T. Johns, F. Li, and Allen Bennett, "A Novel Approach to Fault Diagnosis in Multicircuit Transmission Lines Using Fuzzy ARTMAP Neural Networks," IEEE Trans. Neural Networks, vol. 10 , no. 5 , pp. 1214 - 1221, 1999.

[6] A. De, and N. Chatterjee, "A Fuzzy ARTMAP fault classifier for impulse testing of power transformers," IEEE Trans. Dielectrics and Electrical Insulation, vol. 11, no. 6, pp. 1026 - 1036, 2004.

[7] W. P. Ferreira, M. C. G. Silveira, A. P. Lotufo, C. R. Minussi, "Transient stability analysis of electric energy systems via a Fuzzy ART-ARTMAP neural network," Electric Power Systems Research, vol. 76, no. 6 - 7, pp. 466 - 475, 2006. 


\section{ACCEPTED MANUSCRIPT}

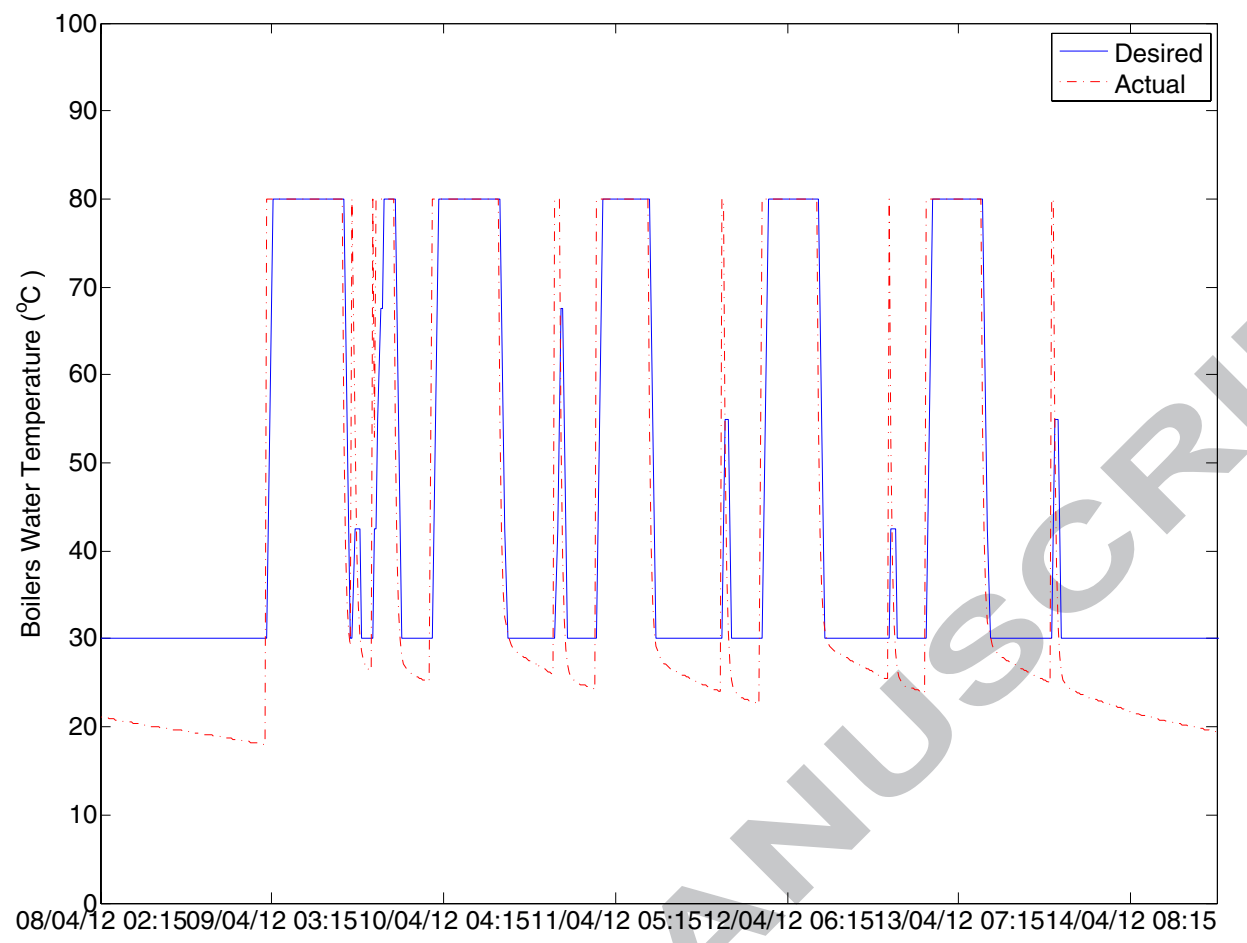

(a) Gaussian ARTMAP

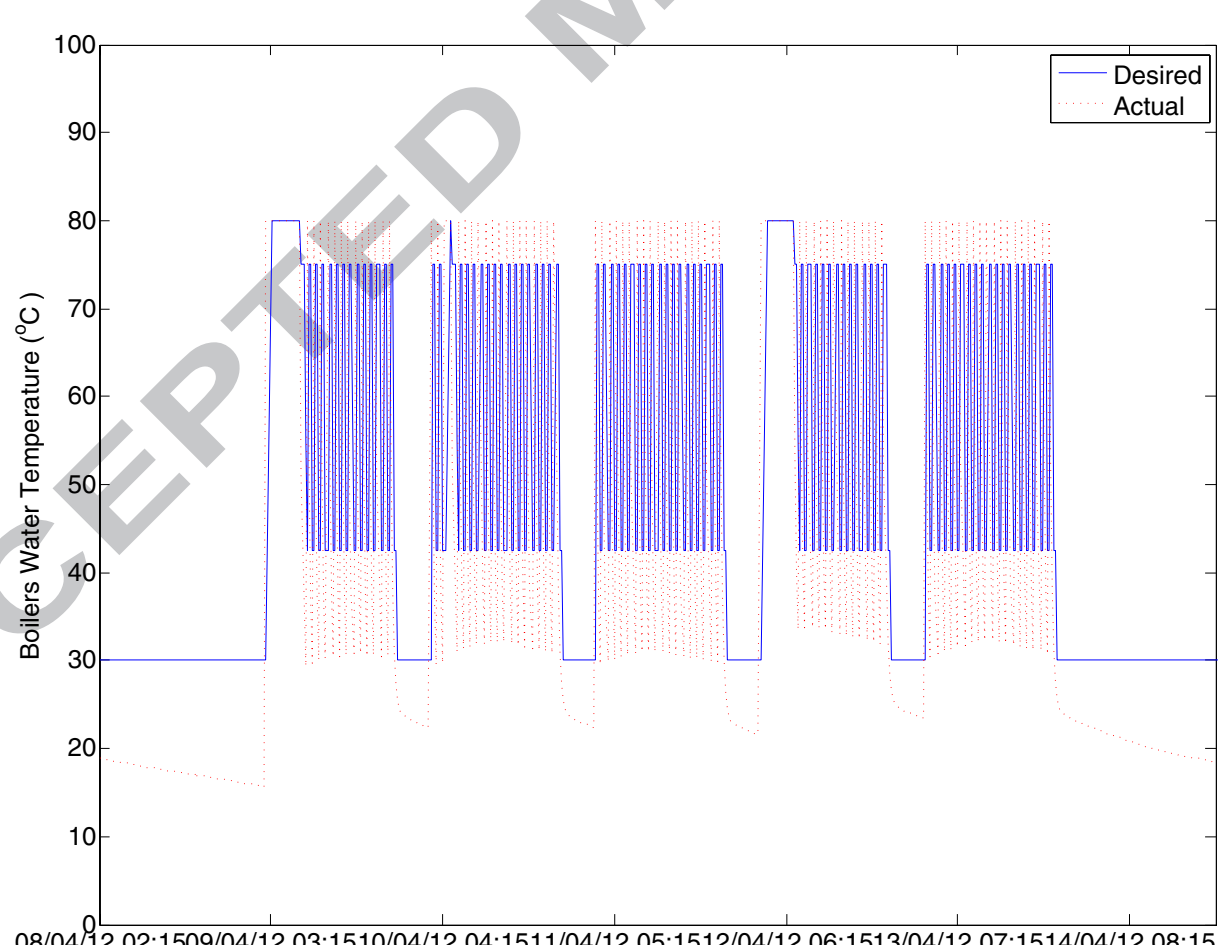

(b) Fuzzy ARTMAP

Figure 6: The desired and actual boilers water temperature for the boilers provided by Gaussian ARTMAP and Fuzzy ARTMAP. 


\section{ACCEPTED MANUSCRIPT}

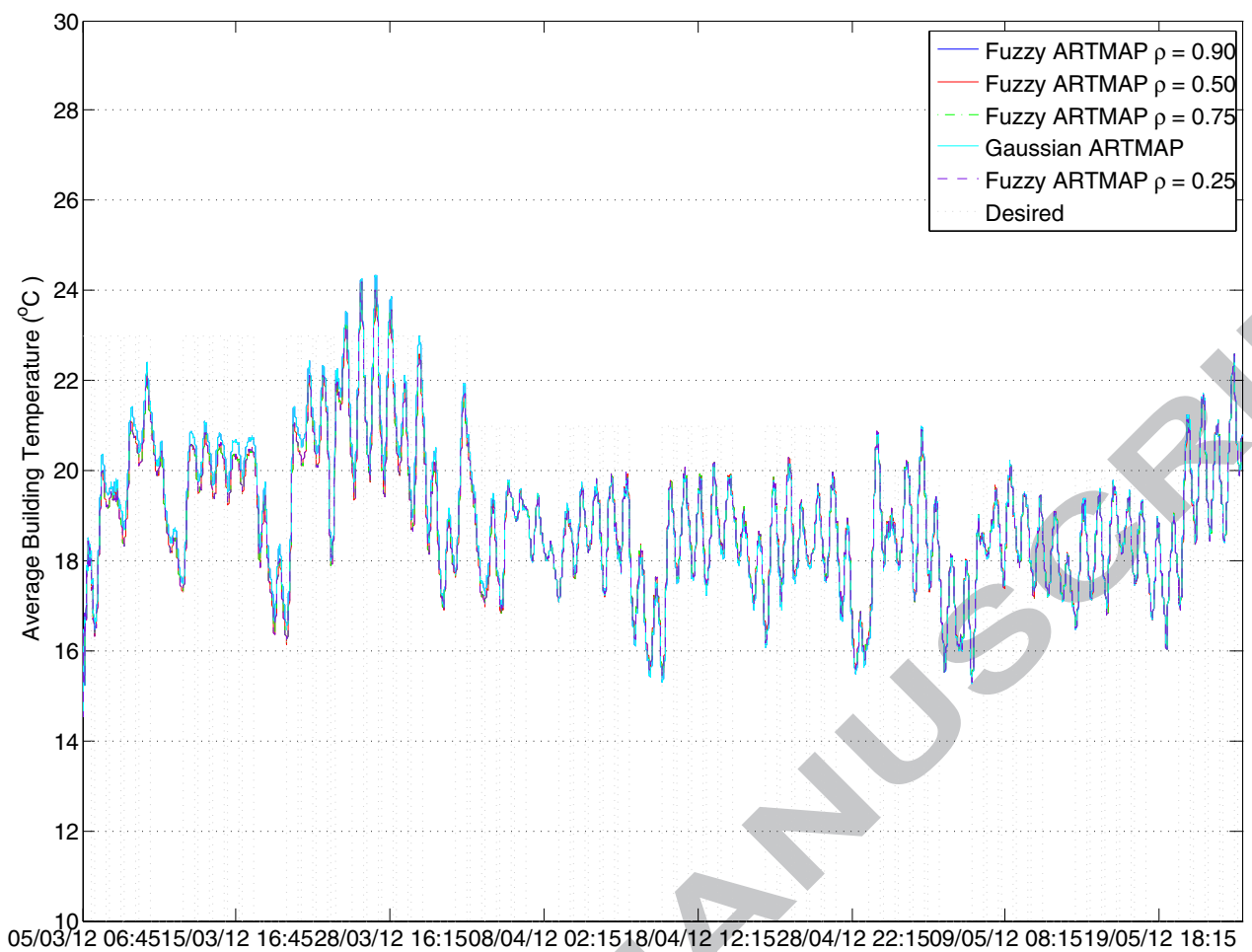

(a) The average building temperature throughout the simulation run

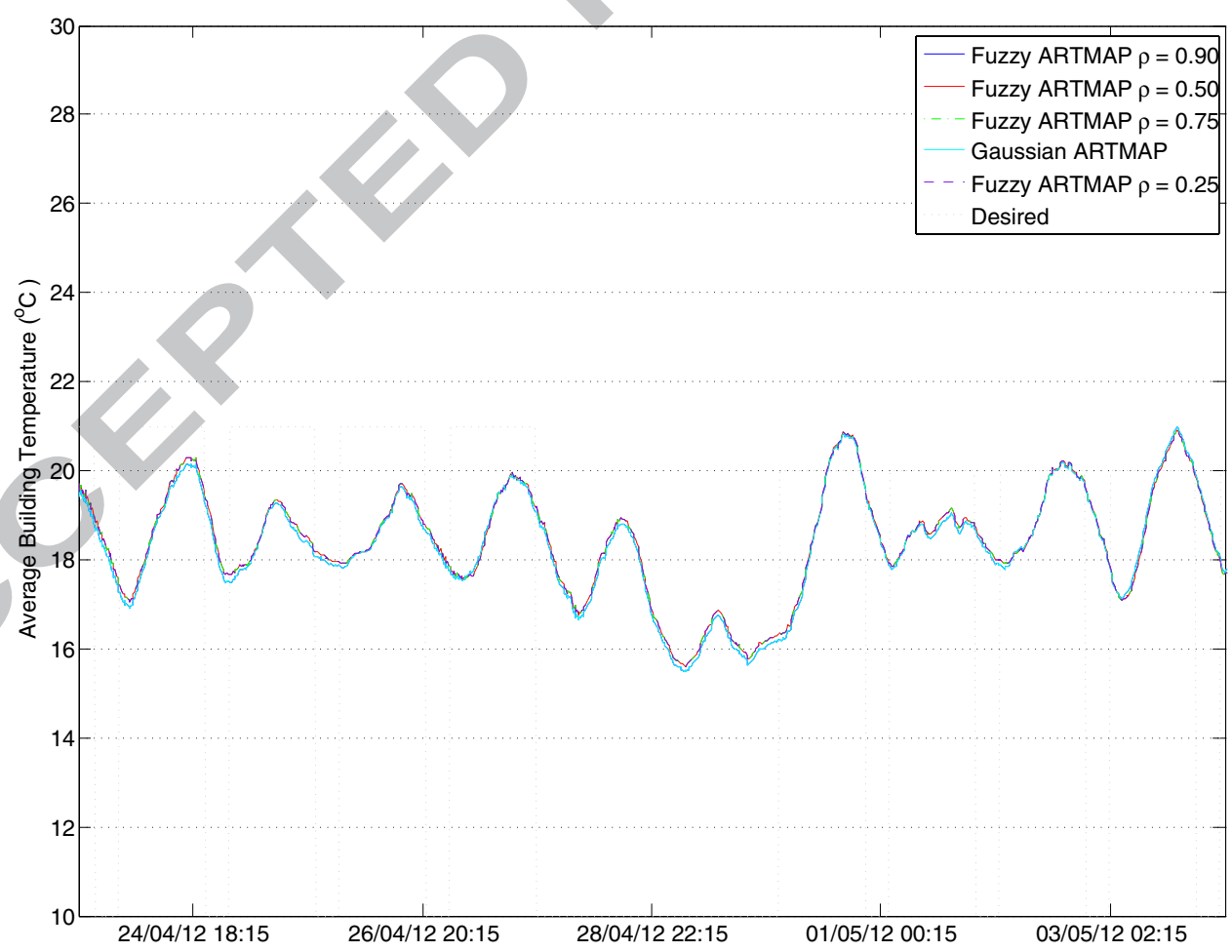

(b) Zooming into a specific time period.

Figure 7: The average building temperature when the control strategies are provided by Gaussian ARTMAP and Fuzzy ARTMAP with varying $\rho$ values. 


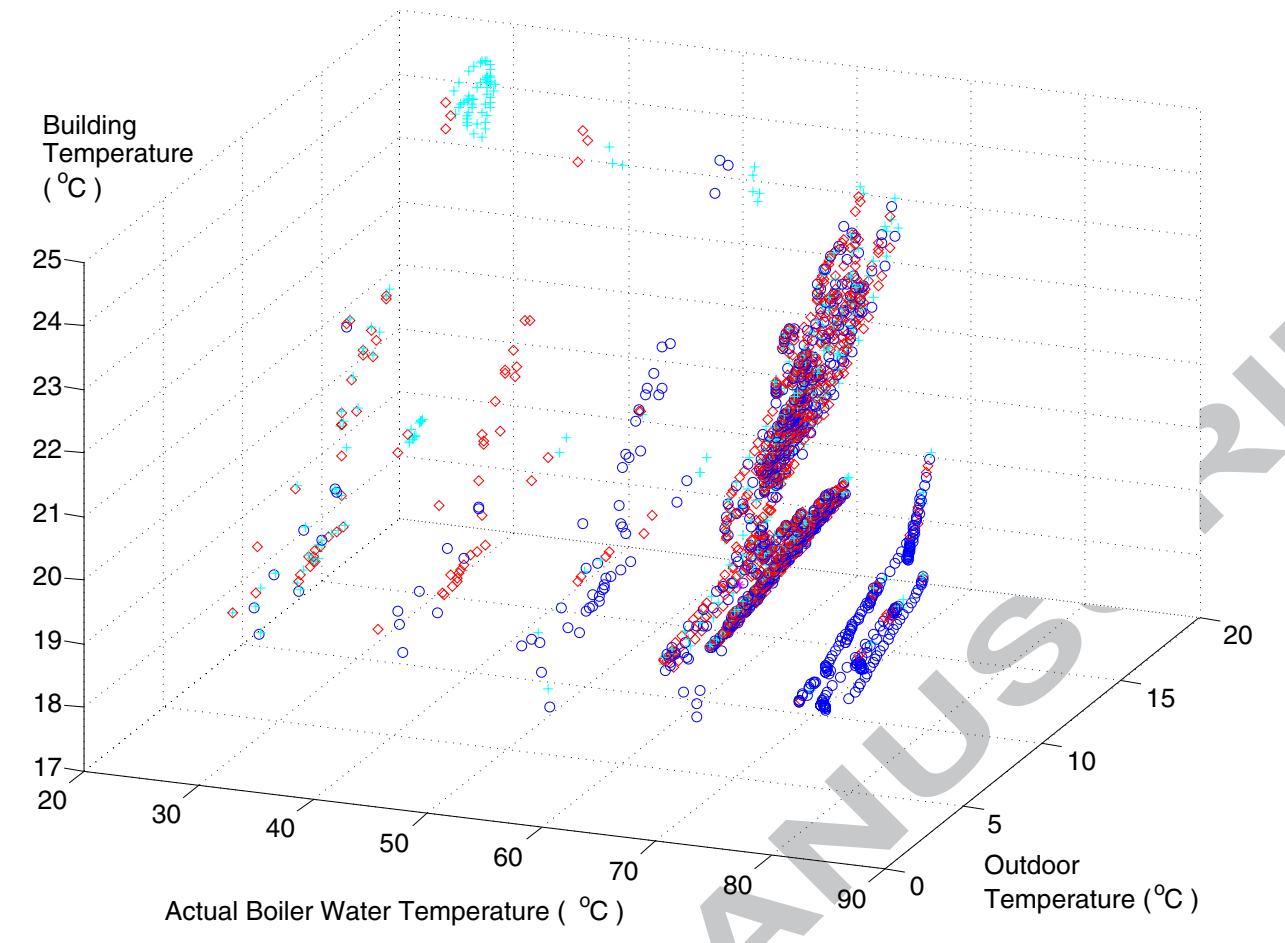

(a) $\rho=0.9$

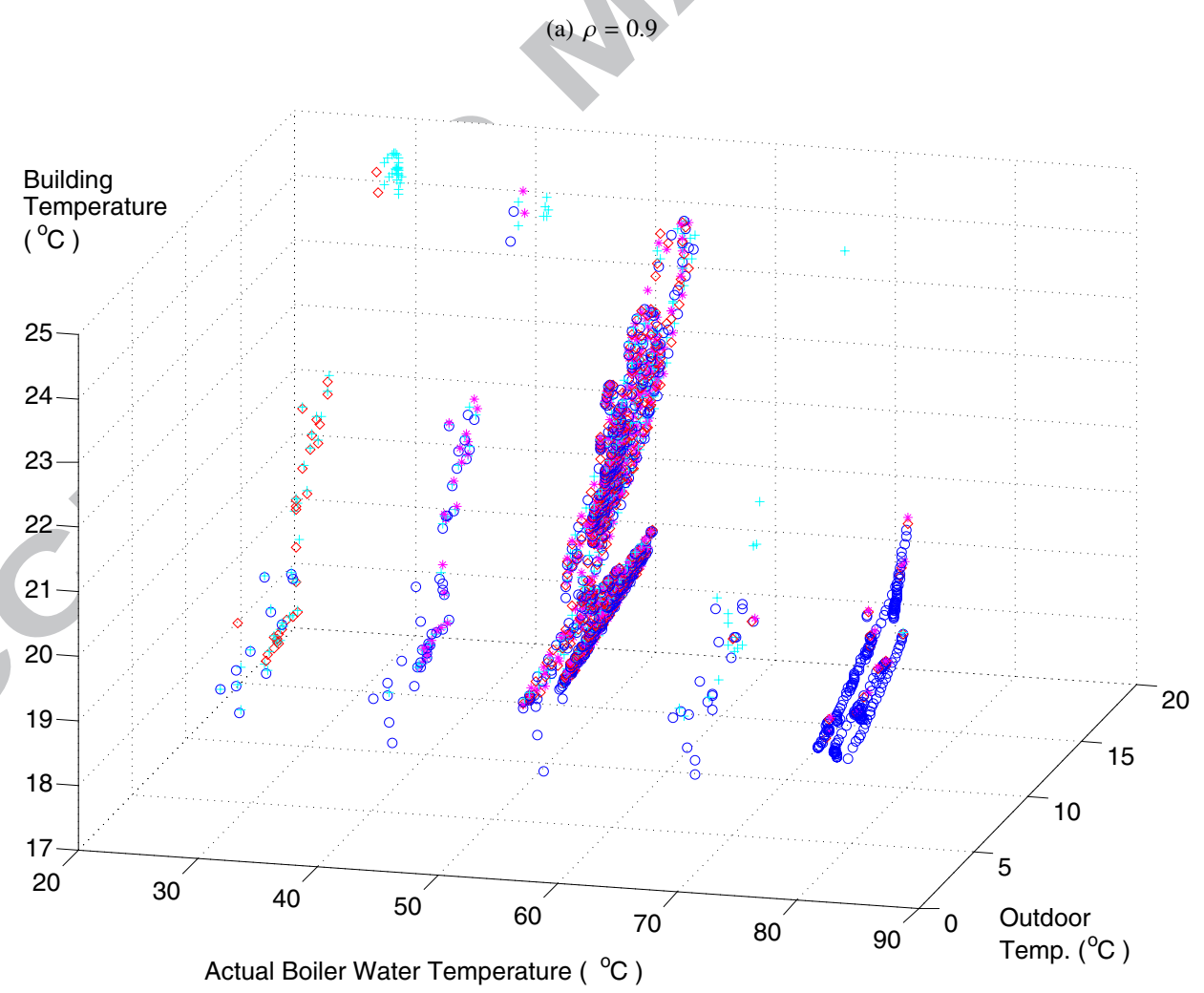

(b) $\rho=0.5$

Figure 8: The four categories produced by Fuzzy ARTMAP with $\rho=0.9$ and $\rho=0.5$, indicating when best to switch ON or OFF the boilers. 


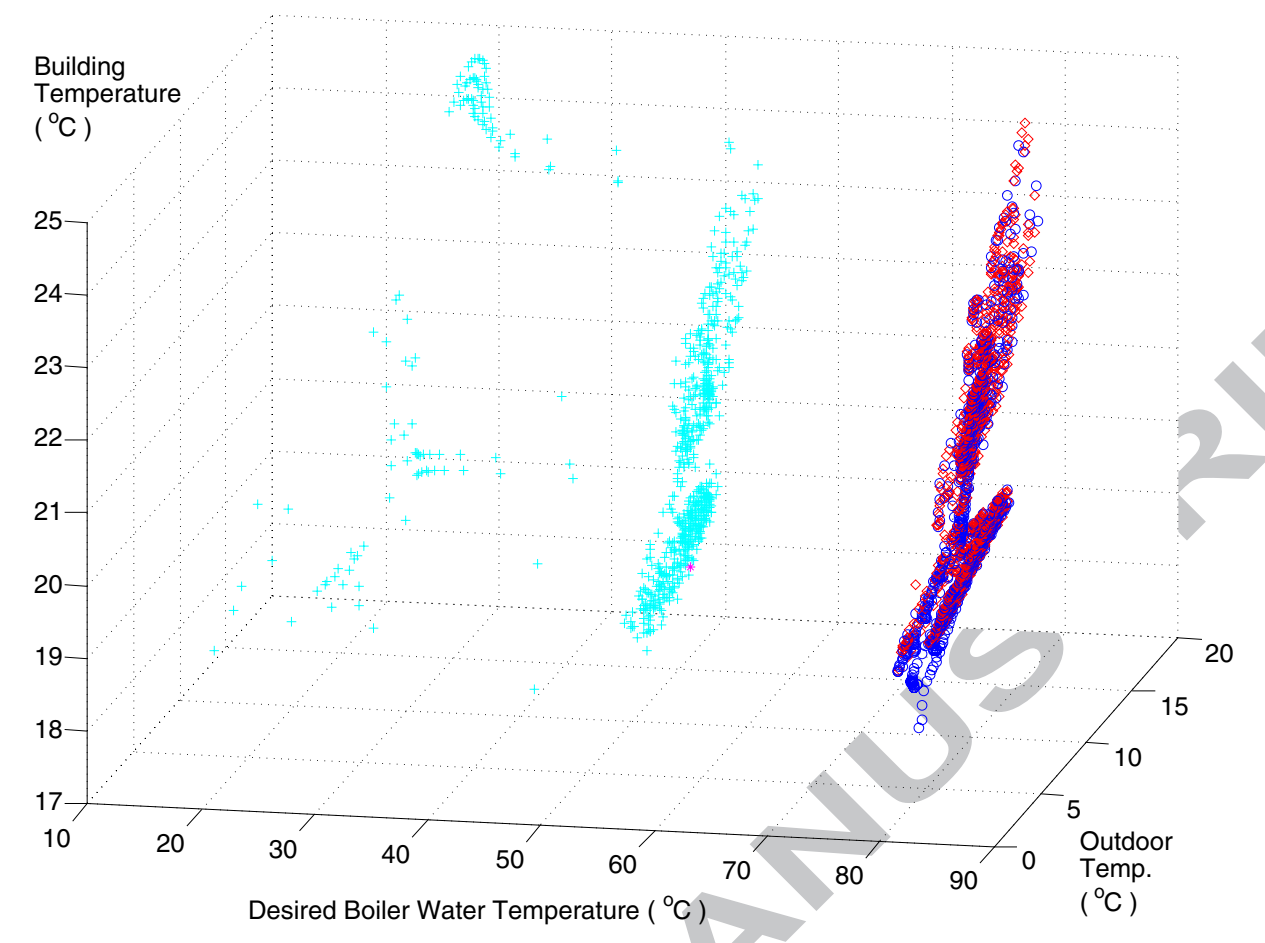

(a) $\rho=0.9$

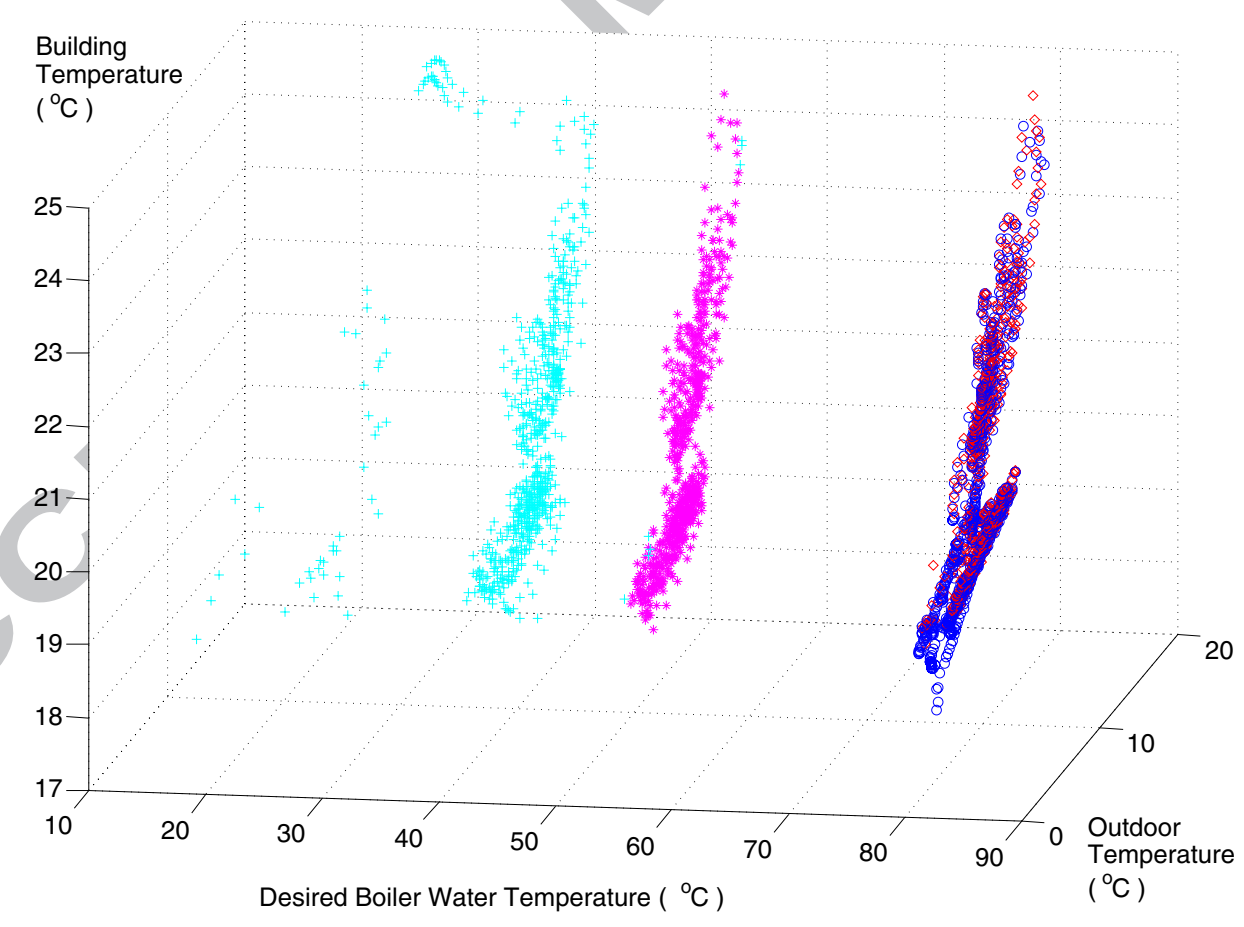

(b) $\rho=0.5$

Figure 9: The four categories produced by Fuzzy ARTMAP with $\rho=0.9$ and $\rho=0.5$, indicating the desired water temperature of the boilers. 
[8] J. G. M. S. Decanini, M. S. Tonelli-Neto, F. C. V. Malange, C. R. Minussi, "Detection and classification of voltage disturbances using a FuzzyARTMAP-wavelet network," Electric Power Systems Research, vol. 81, no. 12, pp. 2057 - 2065, 2011.

[9] M. L. M. Lopes, C. R. Minussi, and A. D. P. Lotufo, "Electric load forecasting using a Fuzzy ART \& ARTMAP neural network," Applied Soft Computing, vol. 5, no. 2, pp. 235 - 244, 2005.

[10] S. Chakraborty, M. D. Weiss, and M. G. Simões, "Distributed Intelligent Energy Management System for a Single-Phase High-Frequency AC Microgrid," IEEE Trans. Industrial Electronics, vol. 54, no. 1, pp 97 - 109, 2007.

[11] A. U. Haque, J. Meng, "Short-term wind speed forecasting based on fuzzy ARTMAP," International Journal of Green Energy, vol. 8, no. 1, pp. 6580, 2011.

[12] J. R. G. Cascales, F. V. García, J. M. C. Izquierdo, J. P. D. Marín, R. M. Sánchez, "Modelling an absorption system assisted by solar energy," Applied Thermal Engineering, vol. 31, no, 1, pp. 112 - 118, 2011.

[13] M. Mokhtar, and X. Liu, "An ARTMAP-incorporated Multi-Agent System for Building Intelligent Heat Management", in The 3rd IEEE-PES European Conference on Innovative Smart Grid Technologies (ISGT- EUROPE 2011), 2011.

[14] R. Palaniappan, R. Paramesran, S. Nishida, and N. Saiwaki, "A New Brain-Computer Interface Design UsingFuzzy ARTMAP", IEEE Transactions on Neural Systems and Rehabilitation Engineering, vol. 10, no. 3, pp 140 - 148, 2002.

[15] R. Andonie, L. Fabry-Asztalos, C. B. Abdul-Wahid, S. Abdul-Wahid, G. I. Barker, and Lukas C. Magill, "Fuzzy ARTMAP Prediction of Biological Activities for Potential HIV-1 Protease Inhibitors Using a Small Molecular Data Set," IEEE/ACM Trans. Computational Biology and Bioinformatics, vol. 8, no. 1, pp. 80 - 93, 2011.

[16] C. L. C. Mattos, G. A. Barreto, "ARTIE and MUSCLE models: building ensemble classifiers from fuzzy ART and SOM networks," Neural Computing and Applications, 2011.

[17] J.F. Connolly, E. Granger, R. Sabourin "Dynamic multi-objective evolution of classifier ensembles for video face recognition," Applied Soft Computing, 2012.

[18] C. Wong, M. Versace, "CARTMAP: a neural network method for automated feature selection in financial time series forecasting," Neural Computing and Applications, vol. 21, no. 5, pp 969-977, 2012

[19] A. Garrett, "Fuzzy ART and Fuzzy ARTMAP Neural Networks," 2003, [Online] http://www.mathworks.com/matlabcentral/fileexchange/4306 
Highlights

1. We created a UCLan Westlakes Samuel Lindow Building heat simulation model.

2. We created a Fuzzy ARTMAP Building Energy Management System with online learning.

3. We created a Gaussian ARTMAP Building Energy Management System with online learning.

4. We compared which of the two creates a more efficient Building Energy Management System.

5. Gaussian ARTMAP is better for use in Building Energy Management System with online learning. 